\title{
CARACTERIZAÇÃO HIDROGRÁFICA DA PLATAFORMA CONTINENTAL DO MARANHÃO A PARTIR DE DADOS OCEANOGRÁFICOS MEDIDOS, REMOTOS E MODELADOS
}

\author{
Alex Costa da Silva ${ }^{1}$, Moacyr Araujo² e Lidriana de Souza Pinheiro \\ Recebido em 6 junho, 2007 / Aceito em 27 setembro, 2007 \\ Received on June 6, 2007 / Accepted on September 27, 2007
}

\begin{abstract}
The objective of this work is to characterize the spacial variability of the thermohaline surface properties in the Maranhão continental shelf and adjacent oceanic area, during two different periods, associated to the distinct characteristics of atmospheric and continental forcings - November/1997 and June/1999. This paper presents the results of simultaneous shipboard measurements collected during oceanographic cruises of the program "REVIZEE/SCORE-NO". Numerical model outputs and satellite data complement the results of hydrographical observations. In the inner shelf (limited at isobath $50 \mathrm{~m}$ ), the distributions of salinity and temperature are mainly affected by fresh water discharge (observed during June/1999). The distributions of SST in the adjacent oceanic region can be explained by the influence of the North Brazil Current (NBC). Model results and hydrographic observations indicate that the mixed layer depth in the oceanic region adjacent to the Maranhão continental shelf is influenced by seasonal variability of the NBC transport associated with the position and the intensification of the high salinity core of the NBC.
\end{abstract}

Keywords: Maranhão continental shelf, hydrography, satellite data, numerical modelling, Program REVIZEE.

RESUMO. Este trabalho tem como objetivo analisar a variabilidade sazonal das propriedades termohalinas na Plataforma Continental do Maranhão (PCM) e área oceânica adjacente. Foram considerados dois diferentes períodos, associados às distintas características de forçantes atmosféricas e continentais - Novembro/1997 e Junho/1999. Os resultados foram baseados na análise simultânea de dados hidrográficos obtidos a partir de cruzeiros oceanográficos do Programa "REVIZEE/ SCORE-NO", complementados com informações oriundas de satélites e de resultados de modelagem numérica oceânica. Na região da Plataforma Continental Interna (limitada pela isóbata de $50 \mathrm{~m}$ ), as distribuições de salinidade e temperatura são principalmente afetadas pelo aporte continental de água doce, sobretudo no mês de Junho/1999. Na região oceânica adjacente à Plataforma Continental (ao longo da quebra da plataforma), as distribuições de TSM podem ser explicadas com base na influência da Corrente Norte do Brasil (CNB). Os resultados numéricos e as observações hidrográficas confirmam que a profundidade da camada de mistura na região oceânica adjacente à PCM é fortemente condicionada à posição e à intensificação dos núcleos de salinidade máxima, que por sua vez são influenciados pela variabilidade sazonal da CNB

Palavras-chave: Plataforma Continental do Maranhão, hidrografia, dados de satélite, modelagem numérica, Programa REVIZEE.

\footnotetext{
1 Universidade Estadual do Ceará, CCT, LGCO, Av. Paranjana, 1.700, Campus do Itaperi - 60740-000, Fortaleza, CE, Brasil. Tel./Fax: +55 (85) $3101-9786$ -E-mails: alexcs@uece.br / lidriana@uece.br

${ }^{2}$ Laboratório de Oceanografia Física Estuarina e Costeira, Departamento de Oceanografia da Universidade Federal de Pernambuco (LOFEC/DOCEAN/UFPE), Av. Arquitetura s/n, Campus Universitário - 50739-540, Recife, PE, Brasil. Tel./Fax: +55 (81) 2126-8225 - E-mail: moa@ufpe.br
} 


\section{INTRODUÇÃo}

A Temperatura da Superfície do Mar (TSM) e a Salinidade da Superfície do Mar (SSM) nas regiões tropicais e subtropicais do planeta estão sendo vistas e estudadas como variáveis de estado importantes na troca de calor oceano-atmosfera, e, conseqüentemente, na previsão das variações climáticas remotas e/ou locais (Hastenrath, 1984; Nobre \& Shukla, 1996). A variabilidade da TSM, por exemplo, exerce influência sobre as ocorrências de tempestades e tormentas tropicais (Shapiro \& Goldenberg, 1998; DeMaria et al., 2001), a maior ou menor duração de estiagens (Moura \& Shukla, 1981), ou mesmo sobre as distribuições de flora e fauna marinha (Marra et al., 1990; Ciotti et al., 1995).

Se em épocas anteriores as medidas da TSM e SSM só poderiam ser feitas através de campanhas oceanográficas, nos últimos anos, 0 avanço tecnológico permitiu que estas variáveis sejam estimadas e interpretadas a partir de informações de reflectância obtidas por sensores instalados em satélites. Ao mesmo tempo modelos numéricos oceânicos vêm sendo cada vez mais utilizados como ferramenta importante na análise e previsão da distribuição espacial e temporal destas variáveis. Neste artigo será dada ênfase à análise de dados hidrográficos obtidos in situ (cruzeiros oceanográficos), gerados a partir de registros de satélite, e resultantes da utilização de técnica de modelagem matemática.

A região de interesse neste estudo se localiza na borda oeste do Atlântico equatorial, mais especificamente na região costeira do litoral amazônico, região em que se efetua boa parte do transporte de calor e massa que ocorre entre os hemisférios (Stramma \& Schott, 1999; Stramma et al., 2003; 2005). Ao longo da costa norte brasileira atua em superfície a Corrente Norte do Brasil (CNB), transportando águas quentes e salinas do hemisfério sul em direção noroeste. Em profundidade, as águas frias formadas no Atlântico Norte transitam em direção sul, via a Corrente Profunda de Borda Oeste (CPBO). Este esquema de circulação foi denominado de circulação termohalina do Atlântico (Gordon, 1986), constituindo uma parte do que se costuma designar por "esteira transportadora" da circulação termohalina do oceano global.

A região atlântica equatorial está sob influência da variabilidade espaço-temporal da Zona de Convergência Intertropical (ZCIT). Dessa forma, verifica-se que durante os meses de janeiro a junho (inverno austral) são observadas chuvas mais fortes e com maior frequêencia na região Amazônica, período este em que a ZCIT se encontra em sua posição mais ao sul, alcançando a área costeira e oceânica próximas do equador. Por outro lado, os meses de setembro a novembro, que caracterizam 0 verão austral, são marcados por menores taxas de precipitações, associados à posição da ZCIT, que neste período do ano se encontra deslocada para o hemisfério norte (Silva, 2006, entre outros).

Associadas à variabilidade da ZCIT, a ação do cisalhamento eólico na área de estudo é mais forte de janeiro a julho, com ventos fluindo de nordeste, incidindo quase que perpendicularmente à costa, e atingindo uma velocidade máxima em média de $10 \mathrm{~m} . \mathrm{s}^{-1}$, enquanto que nos meses de outubro a dezembro este ventos são menos intensos e sopram preferencialmente do quadrante leste e sudeste (Geyer et al., 1996; Silva, 2006).

Além das forçantes atmosféricas, esta região sofre uma grande influência do aporte de águas doces provenientes das descargas fluviais dos rios amazônicos. 0 mais caudaloso deles é o rio Amazonas, cuja descarga provoca a formação de uma extensa pluma de água de baixa salinidade, atingindo centenas de quilômetros em direção mar aberto, mais de $1000 \mathrm{~km}$ em direção noroeste, e mesmo penetrando no Oceano Atlântico Norte (Gibbs, 1970; Hellweger \& Gordon, 2002; Silva et al., 2005b; Ffield, 2007).

Este trabalho tem por objetivo analisar as características termohalinas das águas superficiais na Plataforma Continental do Maranhão (referenciada a seguir por PCM) e região oceânica adjacente, utilizando como base dados hidrográficos coletados em dois períodos sazonais distintos, nos meses de Novembro/1997 e Junho/1999. Estas medidas in situ foram obtidas durante os cruzeiros oceanográficos do Programa REVIZEE/SCORE-NO, e serão complementadas neste estudo com informações obtidas por satélites e por resultados de simulação obtidos através do experimento numérico com um modelo oceânico de alta resolução espacial $\left(1 / 6^{\circ}\right)$. Trata-se de uma área de grande dinâmica, resultado da ação combinada do aporte de águas continentais, dos ventos alíseos, e da influência da Corrente Norte do Brasil (CNB) e sua componente em subsuperfície a Subcorrente Norte do Brasil (SCNB), que transporta grande volume d'água para noroeste, paralelamente à costa (Johns et al., 1998; Schott et al., 1998; Silva, 2006).

\section{MATERIAIS E MÉTODOS}

A área de estudo compreende a Plataforma Continental do Maranhão e região oceânica adjacente, sendo limitada pelas coordenadas Lat. $2,5^{\circ} \mathrm{S}-0,5^{\circ} \mathrm{N}$ e Long. $41,0^{\circ} \mathrm{W}-45,0^{\circ} \mathrm{W}$ (Fig. 1).

\section{Dados de mar}

\section{Cruzeiros oceanográficos}

Os dados de mar utilizados neste trabalho foram coletados durante dois cruzeiros oceanográficos realizados em épocas distintas (nos meses de Novembro/1997 e Junho/1999) pelo NOC. 


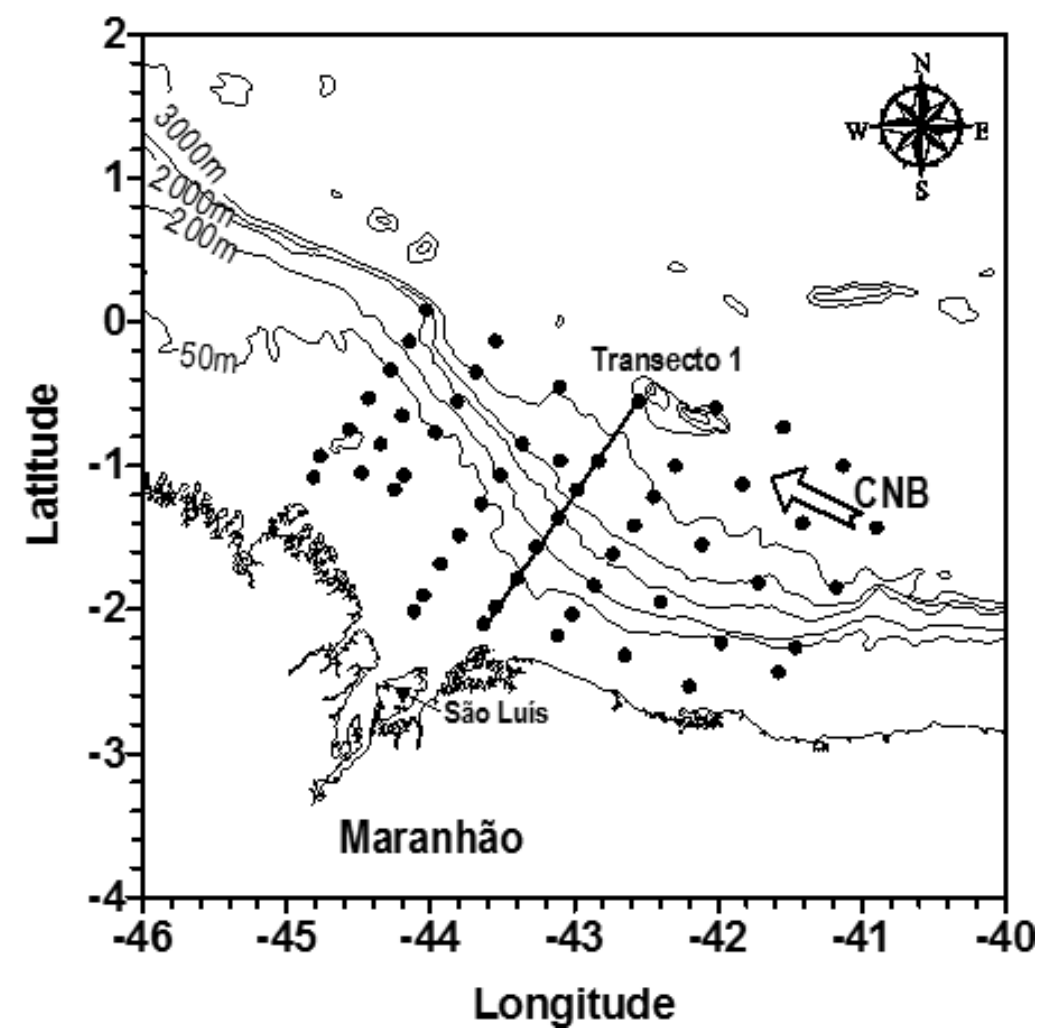

Figura 1 - Mapa de localização da área de estudo, indicando as estações de coleta (CTD), 0 Transecto 1 (perpendicular à costa), e 0 sentido da Corrente Norte do Brasil (CNB), fluindo para Noroeste ao longo da margem continental amazônica. A localização da ilha de São Luís, situada no arquipélago de ilhas do Golfão Maranhense.

Antares, como parte das atividades do Programa REVIZEE/N (Programa Nacional de Avaliação do Potencial Sustentável de Recursos Vivos da Zona Econômica Exclusiva na região Norte do Brasil). 0 Programa REVIZEE, sob coordenação da Comissão Interministerial para os Recursos do Mar (CIRM), é resultado do compromisso que 0 Brasil assumiu perante a Organização das Nações Unidas (ONU), ao ratificar em 1988 a Convenção Internacional da Lei do Mar, em validade desde 1994 (CIRM, 1994). 0 conjunto de dados aqui analisados correspondem as perfilagens verticais realizadas em 56 estações hidrográficas (Fig. 1). Os registros foram obtidos com a utilização de equipamento CTD Sea Bird Electronics SBE911p/us, equipado com bomba centrífuga e sensores de alta resolução para medições de Condutividade (resolução $=0,00004 \mathrm{~S} . \mathrm{m}^{-1}$ ), Temperatura (resolução $=$ $0,0003^{\circ} \mathrm{C}$ ) e Pressão (resolução $=0,068 \mathrm{db}$ ). A salinidade foi calculada com os algoritmos da escala prática (PSS-178), em função da razão de condutividade elétrica, temperatura e pressão (UNESCO, 1981). Os dados de ventos (intensidade e direção) foram medidos com a utilização do anemômetro do NOC. Antares, durante os períodos de coletas das campanhas oceanográficas.
Para os cálculo dos valores médios de intensidade de vento, foram consideradas todas as medidas realizadas ao longo dos períodos de duração das campanhas (cerca de 20 dias).

Critério para a determinação das profundidades das Camadas de Mistura (Z Mix), Isotérmica (Z Isot) e Espessura da Camada de Barreira (ECB)

A camada de mistura é um elemento essencial para a transferência de calor e água entre a atmosfera e os oceanos. Resultados de dados in situ coletados na costa norte do Brasil, demonstram que a salinidade tem um papel significante na variação da profundidade da Camada Isotérmica (ZIsot) e na profundidade da Camada de Mistura ( $Z M i x)$, essa diferença de variação na profundidade da $Z$ Mix e na profundidade da $Z$ I sot é 0 que chamamos de Espessura da Camada de Barreira ( $E C B$ ) (Sprintall \& Tomczak, 1990; Lukas \& Lindstrom, 1991; Cronin \& McPhaden, 2002; Silva et al., 2005a). 0 efeito principal da EC B é promover 0 maior isolamento da camada superficial dos oceanos, dificultando a troca de calor entre a camada de mistura mais aquecida, 
e 0 oceano interior, mais frio. Estas mudanças influenciam, portanto a TSM (Lukas \& Lindstrom, 1991).

A maioria dos critérios utilizados para a determinação da $Z M i x$ nos oceanos considera a localização (profundidade) em que se encontra um determinado valor de temperatura (ou de densidade, $\sigma_{t}$ ) deduzido a partir da TSM (Sprintall \& Tomczak, 1990; Brainerd \& Gregg, 1995; Cronin \& McPhaden, 2002). A Z Mix é então estimada como a profundidade onde a densidade é igual à densidade da água de superfície adicionada de um incremento $\Delta \sigma_{t}$ equivalente à redução de temperatura desejada. Por exemplo, Miller (1976) e Spall (1991) utilizam $\Delta \sigma_{t}=0.125 \sigma_{t}(0)$ para determinar $Z M i x$, enquanto que Sprintall \& Tomczak (1992) e Ohlmann et al. (1996) adotam $\Delta \sigma_{t}=0.5^{\circ} \mathrm{C}\left(\partial \sigma_{t} / \partial T\right)$, onde $\partial \sigma_{t} / \partial T$ é 0 coeficiente de expansão térmica da água. De acordo com Sprintall \& Tomczak (1992), o valor de ZMix neste trabalho foi calculado considerando variações de temperatura e densidade $\left(\Delta T=0.5^{\circ} \mathrm{C}\right.$ e $\Delta \sigma_{t}=0.5^{\circ}\left(\partial \sigma_{t} / \partial T\right)$, respectivamente) com relação às temperaturas e densidade superficiais $(T(0)$ e $\sigma_{t}(0)$, respectivamente) obtidas nos cruzeiros do Programa REVIZEE/N, ou seja:

$$
Z M i x=z\left(\sigma_{t}=\sigma_{t}(0)+\frac{\partial \sigma_{t}}{\partial T} \Delta T\right)
$$

onde $\partial \sigma_{t} / \partial T$ é calculado em função dos valores de SST e SSM específicos (calculado, por exemplo, a partir de Blanck (1999)).

A Equação (1) permite, dessa forma, calcular a Z Mix como sendo igual à profundidade onde a densidade potencial é dada pela densidade da superfície do mar, acrescida da contribuição equivalente a uma variação pré-determinada $\Delta T$. Considerandose agora a profundidade da termoclina (ZIsot) como sendo aquela onde 0 valor de temperatura é igual à temperatura da superfície subtraída de $\Delta T$, tem-se:

$$
E C B=Z_{\text {Isot }}-Z_{\text {Mix }}
$$

onde $E C B(m)$ é a espessura da camada de barreira.

\section{Medidas de satélites}

Temperatura da Superficie do Mar - TSM

Com o objetivo de comparar as medidas realizadas in situ com as estimativas obtidas por satélite, foi calculada a média mensal (Junho/1999) dos dados de TSM fornecida a partir dos registros dos sensores radiométricos passivos instalados a bordo do satélite Tropical Rainfal/ Measuring Mission (TRMM) - Microwave Imager (TMI). Estes dados foram desenvolvidos e reprocessados do satélite TRMM - versão 3.0. 0 TRMM foi lançado em
Novembro de 1997, com uma inclinação orbital de $35^{\circ}$ e altitude de $350 \mathrm{~km}$, com uma órbita equatorial cobrindo de $39^{\circ} \mathrm{N}$ para $39^{\circ} \mathrm{S}$, e com uma resolução de $0,25^{\circ}(\approx 27,75 \mathrm{~km})$. Virtualmente ele cobre a superfície do planeta no período de dois dias, quando os registros são arquivados pelo sensor TMI (Gentemann et al., 2004).

As estimativas dos valores da TSM, obtidas a partir de sensoriamento remoto são fisicamente baseadas em algoritmos que trazem uma resolução espacial de 46 km, e uma precisão (Root Mean Squares ou RMS, medida estatística da importância de uma quantidade variável) de $0,5^{\circ} \mathrm{C}$ (Wentz, 1998). 0 sensor do $T M /$ foi calibrado utilizando-se as informações do SSM/I Sensor Microwave/Imager), com base na metodologia adotada por Wentz et al. (2001). A principal vantagem em se utilizar os dados do TRMM-TMI é a possibilidade da obtenção de estimativas de SST em situações com presença de nuvens, uma vez que a maioria dos sensores infravermelhos são bloqueados com a presença da cobertura de nuvens (Wentz \& Meissner, 2000).

\section{Taxas de Precipitação e Radiação de Onda Longa - ROL}

As taxas mensais de precipitação $\left(\mathrm{mm} . \mathrm{dia}^{-1}\right)$ calculadas ao longo da latitude de $1^{\circ} \mathrm{S}$ e longitude de $45^{\circ} \mathrm{W}-40^{\circ} \mathrm{W}$ utilizadas neste estudo, foram obtidas através dos dados coletados e analisados pelo CPC (Climate Prediction Center, EUA), ao longo dos meses de Novembro/1997 e Junho/1999. A metodologia utilizada pelo CPC para estimar as precipitações inclui a combinação das informações de estações meteorológicas (GTS stations), dos valores de temperatura no topo das nuvens (geostationary infrared) e de sensores dos satélites de precipitação (SSM/I e AMSU-B microwave sensor) (Ferraro et al., 1996; Ferraro, 1997).

Os satélites da série do NOAA - National Oceanic and Atmospheric Administration permitem monitorar os campos de ROL - Radiação de Onda Longa (Gruber \& Krueger, 1984) sobre 0 planeta. Por exemplo, o NCEP (National Center for Environmental Prediction) fornece dois campos diários de ROL. Os arquivos correspondem a médias sobre áreas de $2,5^{\circ} \times 2,5^{\circ}$, correspondentes a uma grade de 73 linhas por 144 colunas. Até há pouco tempo, os valores numéricos de ROL eram estimados a partir dos dados dos sensores HIRS (High Infrared Resolution Spectrometer) do TOVS ou "Tiros Operational Vertical Sounder" no satélite NOAA14; com o objetivo de aprimorar as sondagens em situações de céu aberto e com cobertura de nuvens, atualmente utiliza-se 0 HIRS do ATOVS (Advanced TOVS) no satélite NOAA-16, no caso do NCEP. 0 sistema HIRS está formado por um conjunto de 19 sensores no espectro infravermelho termal, entre 4 e $15 \mu \mathrm{m}$ de comprimento de onda. 
Neste trabalho os dados de ROL foram igualmente modulados e comparados durante os dois distintos períodos de coletas hidrográficas (Novembro/1997 e Junho/1999). Estas informações foram resgatadas do NCEP (Reynolds \& Smith, 1994).

\section{Modelagem Matemática - Experimento ATL6 (1/6 $\left.{ }^{\circ}\right)$}

Durante os anos de 80 e 90, o grupo francês do Programa WOCE (World Ocean Circulation Experiment) concentrou seus esforços em campanhas oceanográficas para investigação da dinâmica das regiões oceânicas do Atlântico sul e equatorial, particularmente sobre as suas bordas oeste e leste. Paralelamente a estas atividades, foram também desenvolvidos programas de pesquisa específicos e complementares, como por exemplo, o Projeto CLIPPER (CLIPPER Project team, 2000; Barnier et al., 2001). 0 objetivo principal do Projeto CLIPPER foi realizar experimentos numéricos de alta resolução visando validar e explorar cientificamente a modelagem da circulação oceânica da bacia do Atlântico, em modo forçado pela atmosfera, e em modo acoplado oceanoatmosfera.

Os resultados apresentados e utilizados nesse trabalho foram gerados a partir do Experimento numérico denominado ATL6 (Alta Resolução no Atlântico $1 / 6^{\circ}$ ), considerado e utilizado por diferentes grupos de pesquisadores como a simulação de referência para o Oceano Atlântico tropical. (Madec et al., 1998; Michel \& Treguier, 2002). As condições iniciais de temperatura (T) e salinidade (S) utilizadas no Experimento ATL6 foram obtidas a partir da climatologia de Reynaud et al. (1998), derivada das medições realizadas nas campanhas do Programa WOCE. Nas simulações foram utilizadas forçantes "realistas" de ventos, fluxos de caIor e de água doce, obtidas para o período do Programa WOCE (1980-1999). Estas informações foram complementadas com os dados diários do European Center for Medium range Weather Forecasting (ECMWF), para os demais períodos de simulação. Ao mesmo tempo, uma nova climatologia mensal de aporte fluvial de águas doce foi fornecida através da publicação da UNESCO (1996). 0 domínio de integração do Experimento ATL6 compreende 0 oceano Atlântico limitado por $98,5^{\circ} \mathrm{W}-30^{\circ} \mathrm{E}$ em Longitude, e $75^{\circ} \mathrm{S}-70^{\circ} \mathrm{N}$ em Latitude, preenchida por uma malha de gride horizontal médio de $1 / 6^{\circ}$ (Gride Mercator). Verticalmente, o oceano foi discretizado em 42 níveis sigma, resultando em uma resolução de $12 \mathrm{~m}$ na superfície e de pouco mais de $200 \mathrm{~m}$ nas regiões mais profundas (abaixo de $1500 \mathrm{~m}$ de profundidade).

Os resultados do modelo para o Experimento ATL6, utilizados neste trabalho, representam uma média de cinco dias dos dados numéricos de temperatura e correntes obtidas em superfície
(5 metros), em mesmos períodos de campanhas oceanográficos realizadas durante o programa REVIZEE/N (Novembro/1997 e Junho/1999).

\section{RESULTADOS}

\section{Ação eólica}

As informações de intensidade e direção dos ventos, coletados durante as duas campanhas oceanográficas, mostram que durante 0 mês de Novembro/1997 os ventos atuantes na região de estudo provêm dos quadrantes Nordeste e Sudeste, com intensidade média em torno de $5,5 \mathrm{~m} \cdot \mathrm{s}^{-1}$ (Fig. 2a). Já durante o mês de Junho/1999, os ventos apresentaram-se com direções preponderantes de Nordeste (mais freqüentes), com intensidade média da ordem de $6,4 \mathrm{~m}_{\mathrm{s}} \mathrm{s}^{-1}$ (Fig. 2b). Dados de médias climatológicos mensais de vento na área de estudo fornecido pelo NCEP para o período de 1997 a 2002, mostram a predominância de ventos alísios de sudeste para o mês de Novembro e a mudança na variação de direção dos ventos alísios de nordeste para sudeste no mês de junho (Fig. 2c).

\section{Temperatura da Superfície do Mar - TSM}

A distribuição superficial da temperatura da água do mar na Plataforma Continental do Maranhão durante o mês de Novembro/1997 apresentou um valor máximo próximo a $28,5^{\circ} \mathrm{C}$, localizado nas proximidades da costa (Fig. 3a). Este período está associado às menores taxas de precipitação na região (Fig. 4a). Durante este período, os menores valores da TSM foram observados na área oceânica adjacente à Plataforma, quando se verifica o aparecimento ou a intrusão de águas oceânicas com baixos valores de temperatura (em torno de $27,6^{\circ} \mathrm{C}$ ).

Durante 0 mês de Junho/1999, época em que se verificam elevadas taxas de precipitação na região (Fig. 4a), a distribuição espacial da TSM apresentou um valor máximo próximo da costa (em torno de $28,9^{\circ} \mathrm{C}$ ), não muito diferente dos valores máximos de temperatura observados durante 0 mês de Novembro/1997 (Fig. 3b). 0 padrão de distribuição de TSM sugere que há influência de águas costeiras, de acordo com núcleos observados de maiores temperaturas. Águas Costeiras apresentam maior concentração de material em suspensão e, conseqüentemente, propicia maior absorção de luz (e calor) nas camadas superficiais. Ao mesmo tempo, dados obtidos e tratados através do NCEP, indicam que os valores de ROL coletados na latitude de $1^{\circ} \mathrm{N}$ não se apresentaram com diferenças significativas entre os dois períodos em análise, com valores ao longo da costa $\left(45^{\circ}-40^{\circ} \mathrm{W}\right)$ no intervalo 254 W.m ${ }^{-2}-266$ W.m $^{-2}$ (Fig. 4b). 

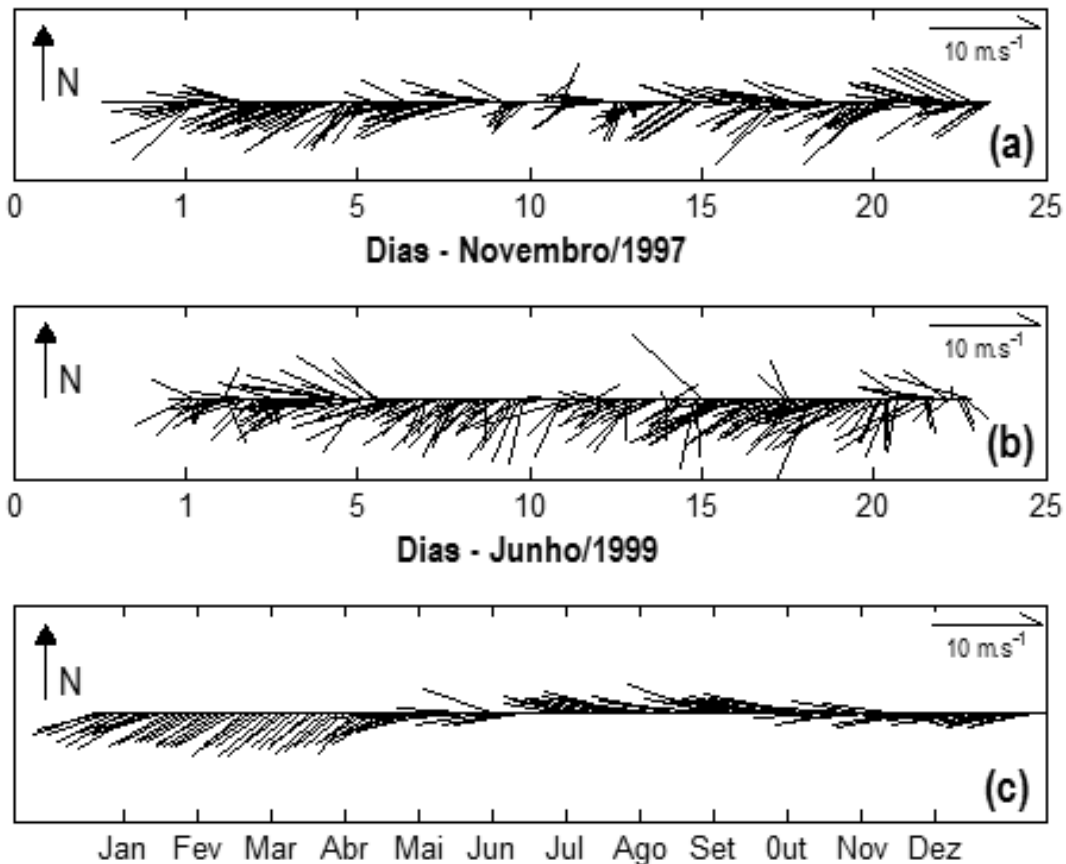

Média Mensal

Figura 2 - Direção e intensidade dos ventos medidas durante as campanhas oceanográficas: Novembro/1997 (a) e Junho/1999 (b). E as médias climatológicas mensais de vento fornecido pelo NCEP para a área de estudo durante o período de 1997 a 2002 (c).
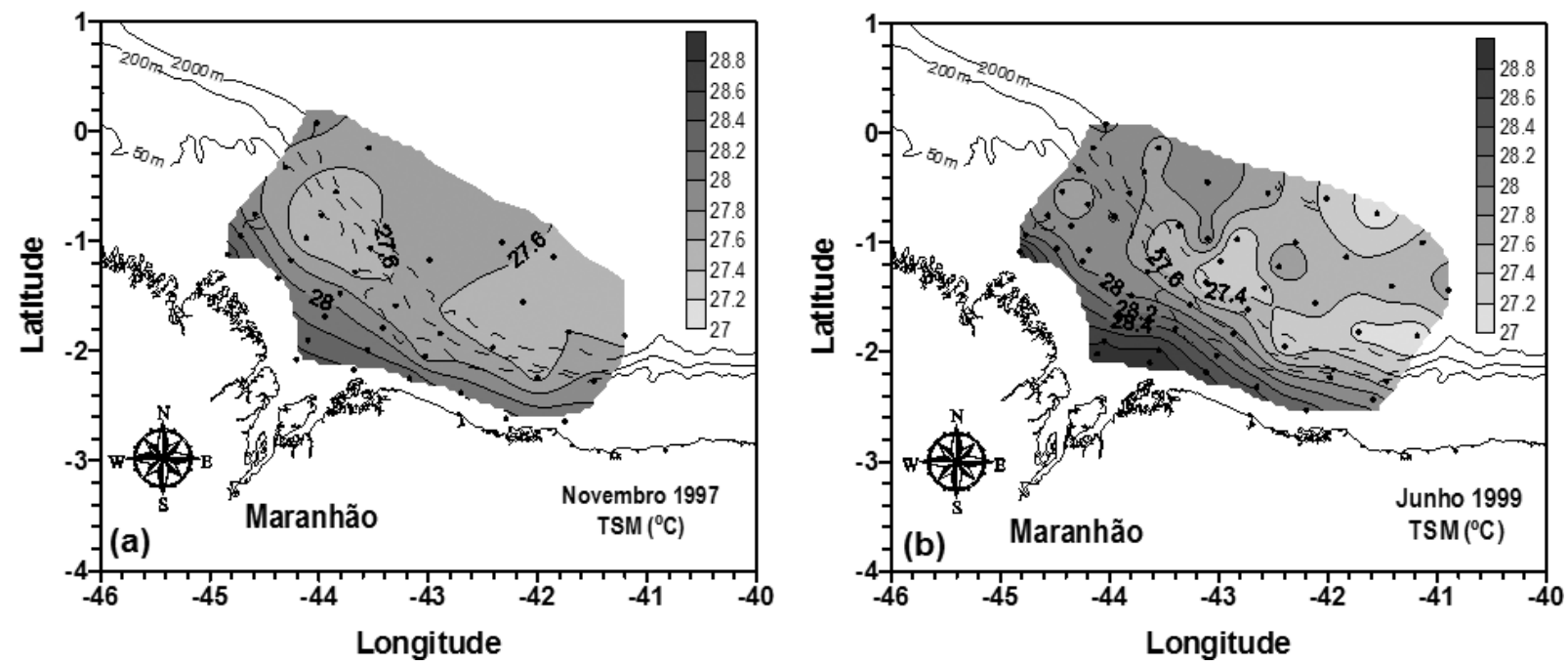

Figura 3 - Cartas de distribuição de Temperatura da Superfície do Mar (TSM), obtidas a partir dos dados hidrográficos coletados nos cruzeiros oceanográficos do Programa REVIZEE/N durante os meses de: (a) Novembro/1997; e (b) Junho/1999.

No que se refere à região oceânica adjacente à Plataforma Continental, os valores da TSM tendem a diminuir mais significativamente em Junho/1999 do que em Novembro/1997, remarcando que durante este período (Junho/1999) foi observado o aparecimento de uma área de baixos valores de $\operatorname{TSM}\left(\leq 27,6^{\circ} \mathrm{C}\right)$ próximo à quebra da Plataforma Continental.

A carta de distribuição da TSM média mensal gerada através de dados do satélite TRMM-TMI, para o mês de Junho/1999, 

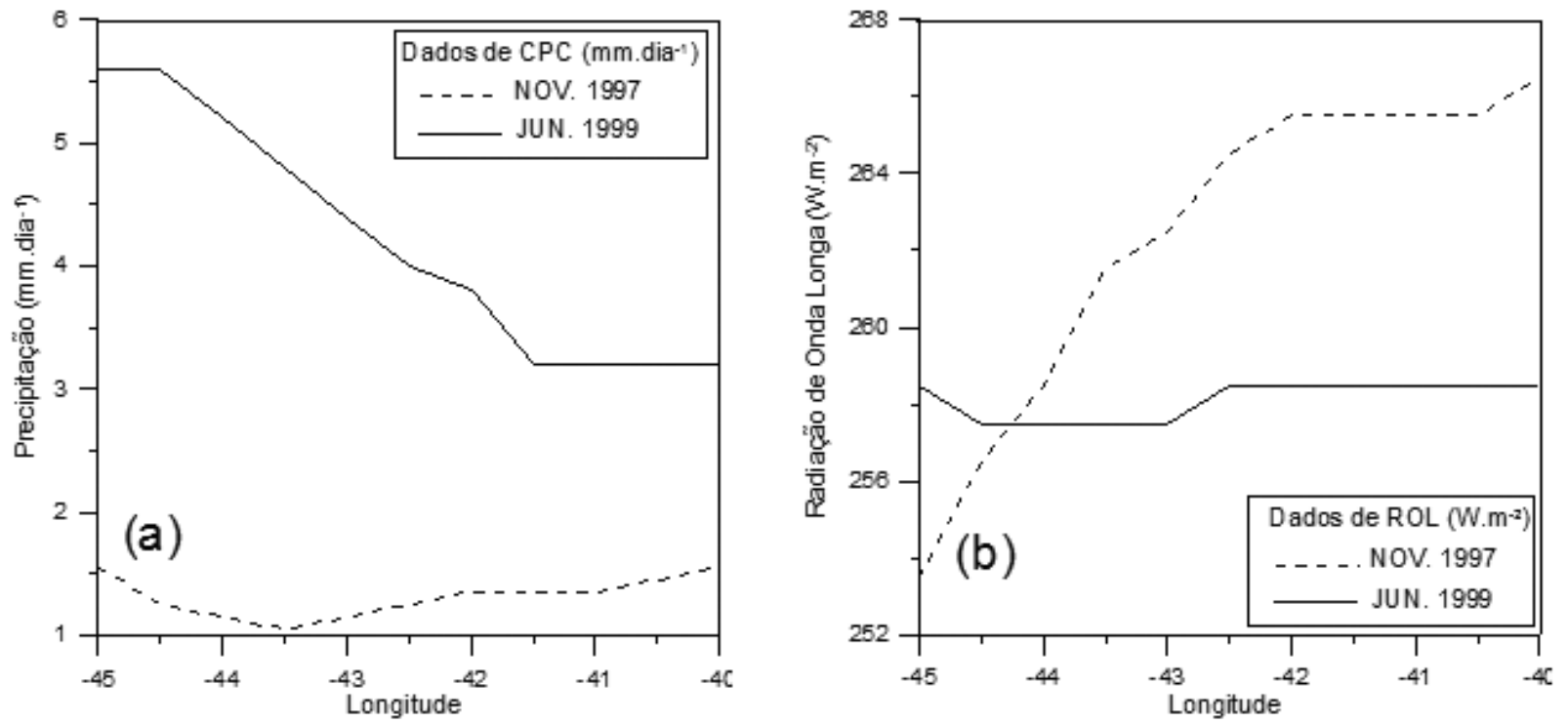

Figura 4 - (a) Dados de precipitação (mm.dia ${ }^{-1}$ ) fornecido pelo CPC - Climate Prediction Center, USA, e (b) dados de OLR - Outgoing Longwave Radiaton $\left(W^{-2} \mathrm{~m}^{-2}\right.$ ), obtidos durante os dois períodos de coletas hidrográficas do Programa REVIZEE/N (Novembro/1997 e Junho 1999).

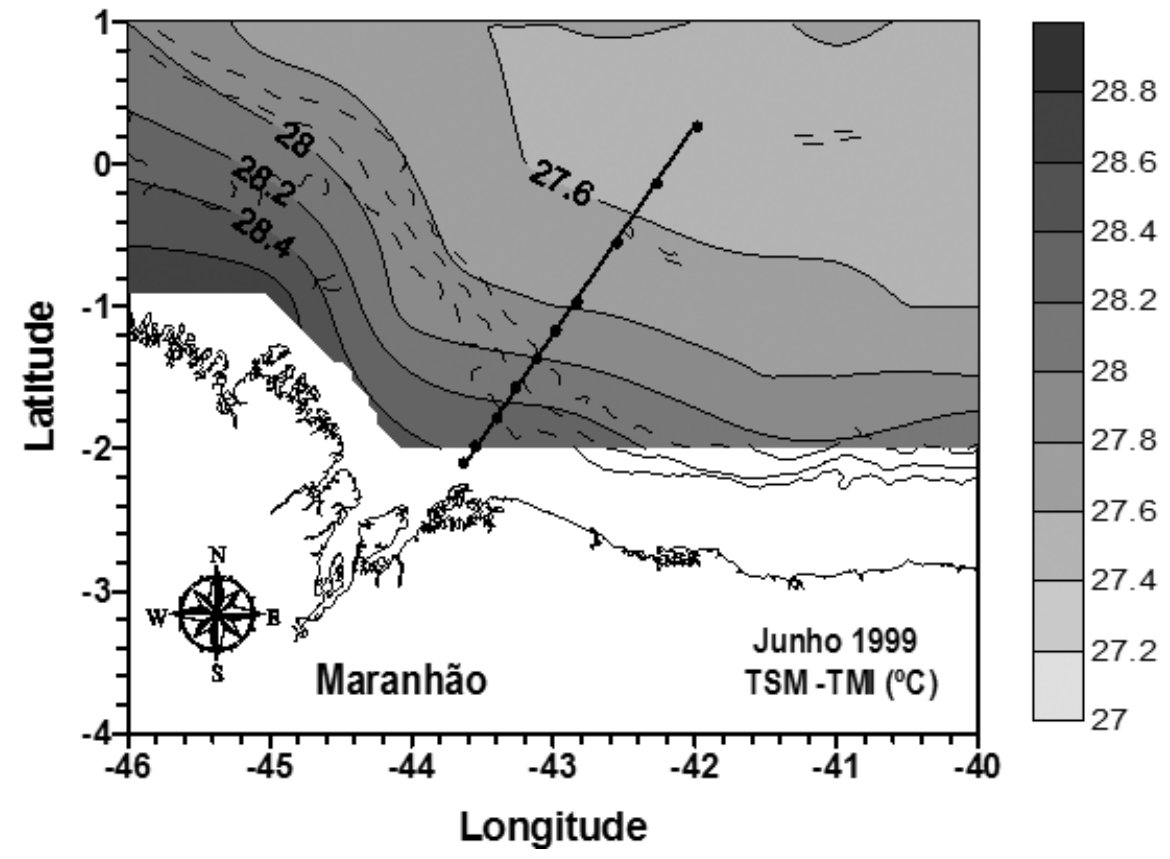

Figura 5 - Carta de distribuição da Temperatura da Superfície do Mar (TSM), obtida a partir de informações do satélite TRMM-TMI, durante o mês de Junho/1999. Localização do transecto e pontos de coletas utilizados na Fig. 9b.

apresentou uma nítida correlação com os dados hidrográficos, quando se registra a presença de altos valores da TSM próximo da costa, e 0 aparecimento de uma faixa de águas mais frias na região oceânica adjacente à quebra da PCM (Fig. 5).

\section{Salinidade da Superfície do Mar - SSM}

As cartas de distribuiçã̃o espacial da Salinidade da Superfície do Mar (SSM), geradas a partir dos cruzeiros oceanográficos do REVIZEE/N, indicam a presença de maiores valores ao longo 
da PCM durante o mês de Novembro/1997, quando comparado ao mês de Junho/1999. Em Novembro registrou-se um valor máximo de SSM de 37,4, diminuindo na direção do mar aberto. 0 valor médio de salinidade para esta época do ano foi de 36,6 (Fig. 6a).

Com relação à distribuição salina para o mês de Junho/1999, observou-se 0 desenvolvimento de duas regiões de baixa salinidade localizadas na porção central/norte da PCM, em frente à ilha de São Luís do Maranhão (em torno de 33,0) e outra na área oceânica adjacente, localizada a NE da Ilha de São Luis do Maranhão (34.5), traduzindo uma nítida influência de águas de origem continental (Fig. 6b). Neste período são verificadas elevadas taxas de precipitação (Fig. 4a). 0 valor de máxima salinidade registrada em Julho/1999 foi de 36,2, obtendo-se ainda uma média de 35,7 para toda a área de estudo.

\section{Estrutura Termohalina Vertical}

A análise dos dados de temperatura e salinidade distribuídos ao longo de um transecto vertical realizado perpendicularmente à costa (Transecto 1, Fig. 1), indica a presença de uma água do mar sobre a PCM com elevados valores de temperatura, em torno de $28^{\circ} \mathrm{C}$, durante os dois distintos períodos de coletas (Figs. $7 a$ e 7b). A temperatura média registrada sobre a PCM (nos primeiros $100 \mathrm{~m}$ de profundidade) em Junho/ 1999 foi de $26,45^{\circ} \mathrm{C}$. Durante o mês de Novembro/1997, verificou-se uma temperatura média de $23,12^{\circ} \mathrm{C}$, bem inferior àquela verificada no mês de Junho/1999.

No Transecto 1 a ZMix foi localizada sobre toda a PCM a cerca de $40 \mathrm{~m}$ de profundidade em ambos os períodos de coleta. Já na região oceânica adjacente à quebra da Plataforma, a ZMix atingiu os 50 metros e a ZIsot alcançou os 60 metros ao longo de todo o transecto, durante o mês de Novembro/1997, formando uma $E C B$ de 10 metros (Figs. 7a e 8a). Durante 0 mês de Junho/1999 as profundidades das ZMix e ZIsot sofreram pequenas elevações a $250 \mathrm{~km}$ de distância do transecto, alcançando as profundidades de 20 metros (ZMix) e 40 metros ( $Z$ Isot), registrando um aumento na $E C B$ de 20 metros (Figs. $7 b$ e 8b). Na região oceânica adjacente à quebra da Plataforma Continental entre as distâncias de 100 a 160 km não se teve formação de $E C B$, observando uma elevação da isoterma de $27,5^{\circ} \mathrm{C}$, atingindo a superfície do mar (Fig. $7 \mathrm{~b}$ ).

A distribuição da salinidade durante 0 mês de Novembro/1997 indica elevados valores de salinidade $(\approx 37,0)$ sobre a PCM, com a presença de águas oceânicas na área da plataforma continental (Fig. 8a). A plotagem do transecto realizada na mesma localidade, durante o mês de Junho/1999, mostra a presença de águas de origem costeira ( $\leq 35.8)$ sobre a PCM e a $300 \mathrm{~km}$ de distância na região oceânica adjacente (Fig. 8b).

Em ambas as épocas do ano verificam-se elevados valores de salinidade $(36,6-36,8)$ na região oceânica adjacente à quebra da PCM, com a presença nítida de núcleos de máxima salinidade. Para o mês de Novembro/1997, por exemplo, este núcleo se encontra mais disperso e centralizado na profundidade de $100 \mathrm{~m}$, enquanto que em Junho/1999 o mesmo é localizado a cerca de 60-70 $\mathrm{m}$ da superfície do mar.

\section{DISCUSSÃO}

Os resultados apresentados nas seções anteriores evidenciam que as propriedades termohalinas características na região da Plataforma Continental do Maranhão, e área oceânica adjacente são influenciadas por um conjunto de processos, que são mais ou menos preponderantes em função da distância da costa e da época do ano.

De acordo com os resultados, a influência das águas continentais é nitidamente marcada na área próxima da costa. Neste sentido, Gibbs (1970), e mais recentemente Silva et al. (2005a; 2005b); Silva (2006), além de outros, têm demonstrado como situação extrema que a pluma d'água superficial com baixo valor de salinidade, resultante da descarga do rio Amazonas, pode atingir centenas de quilômetros da costa na porção oeste e leste do oceano Atlântico equatorial, no qual sofre deslocamento espacial e sazonal por processos advectivos (ventos e correntes). No caso da influência dos aportes continentais oriundos do Golfão Maranhense, esta pluma espalhou-se até uma distância de cerca de 85 km da costa no mês de Junho/1999, época que corresponde aos maiores índices de precipitação na região (Fig. 6b e Fig. 9b).

Além da nítida influência de águas com baixo valor de salinidade sobre PCM durante o mês de Junho/1999, foi também observado na região oceânica adjacente a PCM a presença de águas com baixa salinidade, está pode ser de influência da pluma de água doce proveniente do rio Amazonas. Bourlès et al. (1999) tem mostrado a influência da pluma d'água do rio Amazonas sendo transportada para leste de sua foz na coordenada de $45^{\circ} \mathrm{W}-0,7^{\circ} \mathrm{N}$.

Um outro sinal da ação das águas continentais sobre a estrutura termohalina superficial na PCM está associado aos valores mais elevados (e verificados sobre uma área mais extensa) de temperatura durante Junho/1999, quando comparados aos dados de Novembro/1997 (Figs. 9a e 9b). Tal situação pode ser explicada pelo maior aporte continental de material em suspensão nesta época do ano (maiores descargas fluviais), que inibe a penetração da radiação solar ao longo da coluna d'água, facili- 

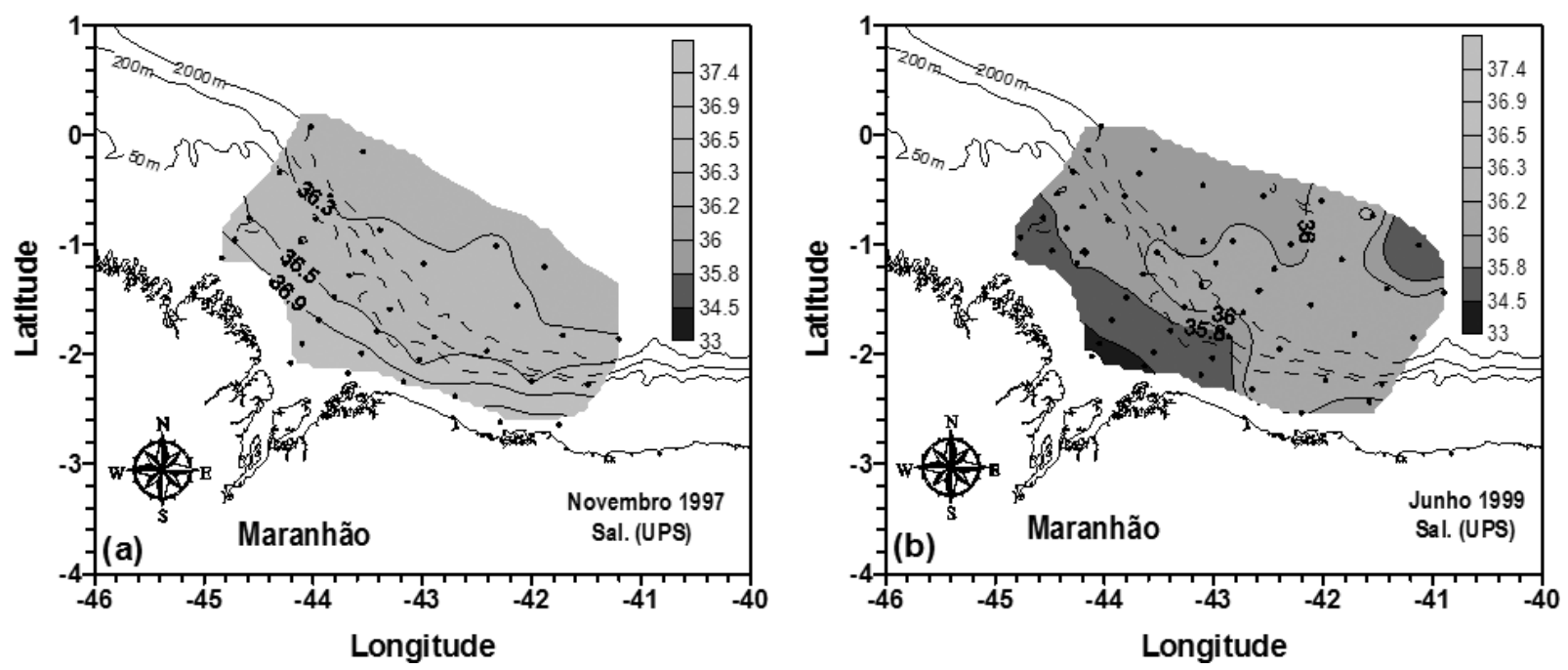

Figura 6 - Cartas de distribuições da Salinidade da Superfície do Mar (SSM), obtidas a partir dos dados hidrográficos coletados nos cruzeiros oceanográficos do Programa REVIZEE/N durante os meses de: (a) Novembro/1997; e (b) Junho/1999.
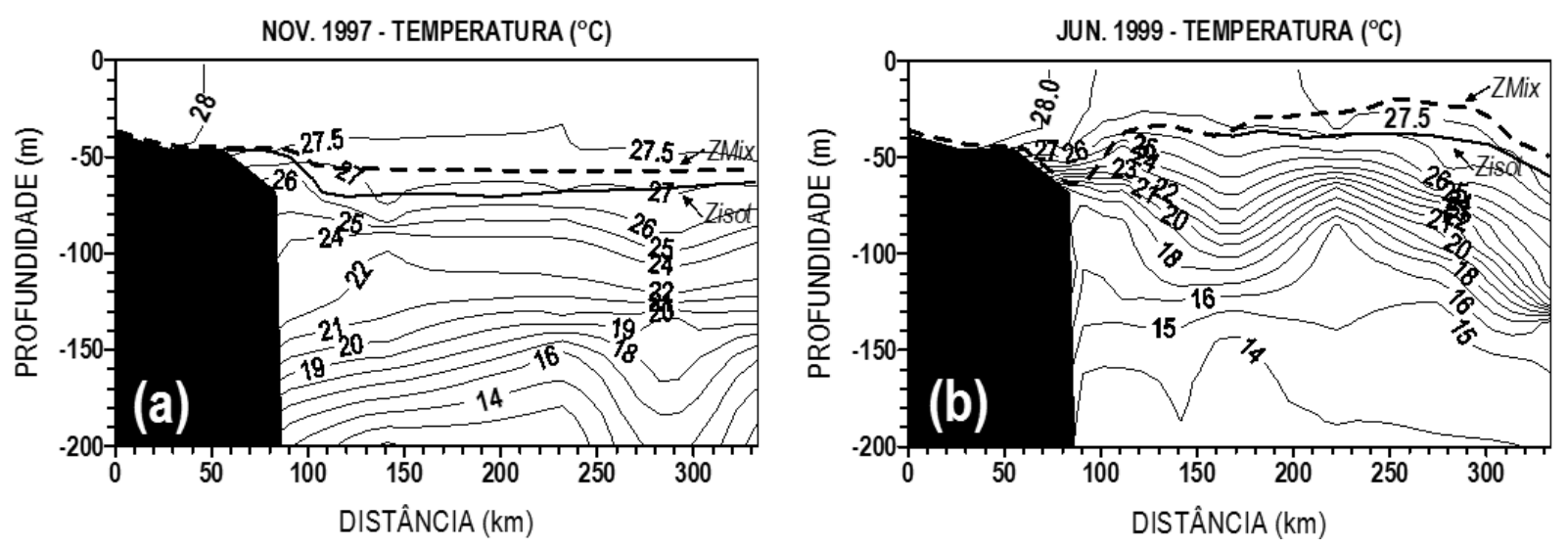

Figura 7 - Perfis verticais (Transecto 1, Fig. 1), indicando a distribuição de temperatura ao longo da profundidade de $200 \mathrm{~m}$ e as profundidades das Camadas de Mistura (ZMix) e Isotérmica (ZIsot), coletados nos cruzeiros oceanográficos do Programa REVIZEE/N, durante os meses de: (a) Novembro/1997; e (b) Junho/1999.

tando 0 aumento de concentração de calor nas camadas superficiais do mar. Ffield (2005), por exemplo, relacionou elevados valores de temperatura na região do Atlântico oeste equatorial, associados à influência de águas com baixos valores de salinidade provenientes do rio Amazonas. A influência dos ventos alísios, principalmente de Nordeste (Junho/1999, Fig. 2b), também contribui no "represamento" da pluma de água mais doce ao longo da costa.

A imagem gerada a partir dos dados de satélite, capturados pelo sensor de microondas do TMI, também mostra a presença de um rastro de baixos valores da TSM na região oceânica adjacente à quebra da Plataforma (Fig. 5), confirmando o que foi obser- vado nas campanhas oceanográficas. Estes resultados também apontam para um decréscimo de valores de TSM à medida que nos afastamos da costa e nos deslocamos para Nordeste (Fig. 5), confirmado experimentalmente pelos valores de temperatura medidos in situ ao longo do Transecto 1 (Fig. 9, posição do transecto Fig. 5). Vale salientar que as medidas de campo (medidas efetuadas pelo CTD) são realizadas em tempo preciso em um ponto escolhido, enquanto que as medidas de satélite são obtidas a partir de valores de reflectância médios. Além disso, os sensores embarcados nos satélites penetram apenas cerca de $1 \mathrm{~mm}$ (sensor de microondas) na camada superficial dos oceanos, enquanto que as primeiras medidas no mar com os sensores do 

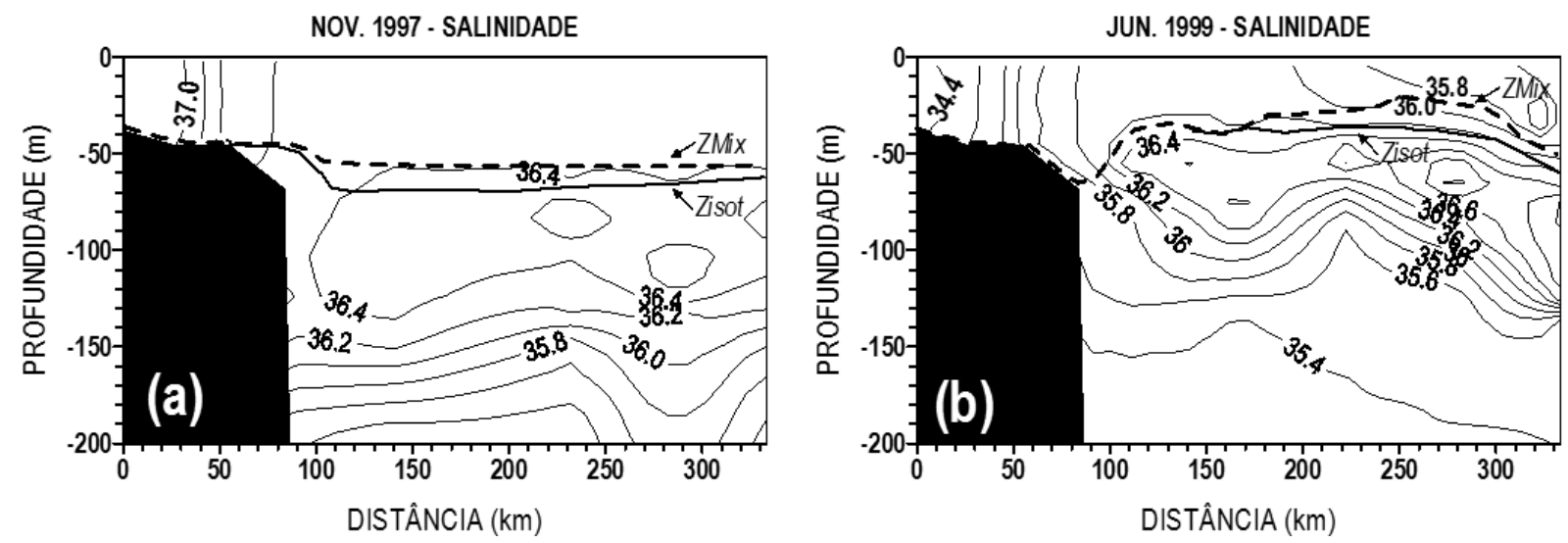

Figura 8 - Perfis verticais (Transecto 1, Fig. 1), indicando a distribuição dos valores de salinidade ao longo da profundidade de 200 m e as profundidades das Camadas de Mistura (ZMix) e Isotérmica (ZIsot), coletados nos cruzeiros oceanográficos do Programa REVIZEE/N, durante os meses de: (a) Novembro/1997; e (b) Junho/1999
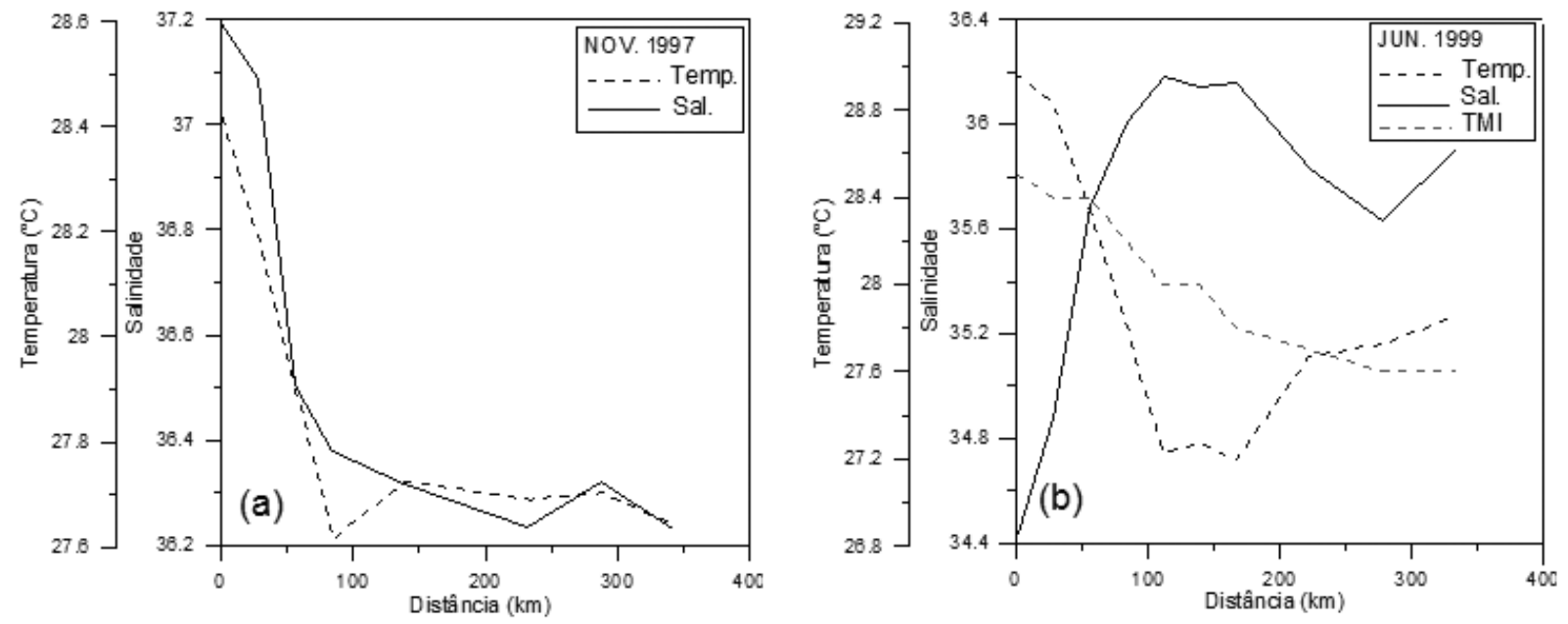

Figura 9 - Perfis longitudinais transversais à costa (Transecto 1, Fig. 1), indicando os valores de Temperatura da Superfície do Mar (TSM) e Salinidade da Superfície do Mar (SSM), coletados nos cruzeiros oceanográficos do Programa REVIZEE/N, e obtidos a partir de dados do satélite TRMM-TMI (Fig. 5), durante 0S meses de: (a) Novembro/1997; e (b) Junho/1999

CTD são localizadas a partir de $1 \mathrm{~m}$ de profundidade (Gentemann et al., 2004).

Na região oceânica adjacente à Plataforma Continental, menos sujeita às influências continentais, verifica-se que as distribuiç̧ões espaciais e sazonais da TSM registradas a partir de resultados do Experimento numérico ATL6 (Fig. 10) são compatíveis com as expectativas geradas pela influência da variabilidade espaço-temporal da Corrente Norte do Brasil (CNB). No período de Novembro/1997 e Junho/1997 (Fig. 10a e Fig. 10b), foram registrados os menores valores de TSM próximo da quebra da PCM. 0 período que corresponde 0 inverno austral (Ju- nho/1999) é caracterizado pela alta capacidade de transporte do sistema Subcorrente Norte do Brasil-Corrente Norte do Brasil (SCNB-CNB) na área de estudo, com volume transportado de 26.7 Sv na longitude de $44^{\circ} \mathrm{W}$ (Bourlès et al., 1999). Medidas de correntes fornecidas por bóias oceanográficas realizadas por Johns et al. (1998) em torno de $4^{\circ} \mathrm{S}$ de latitude, demonstraram que a CNB tem um significante ciclo anual na área, com máximo transporte de 36 Sv em Julho-Agosto e mínimo transporte de 13 Sv em Abril-Maio, com uma média anual em torno de 26 Sv. Estas observações são bem reproduzidas pelas simulações numéricas do Experimento ATL6, quando se verifica uma maior 

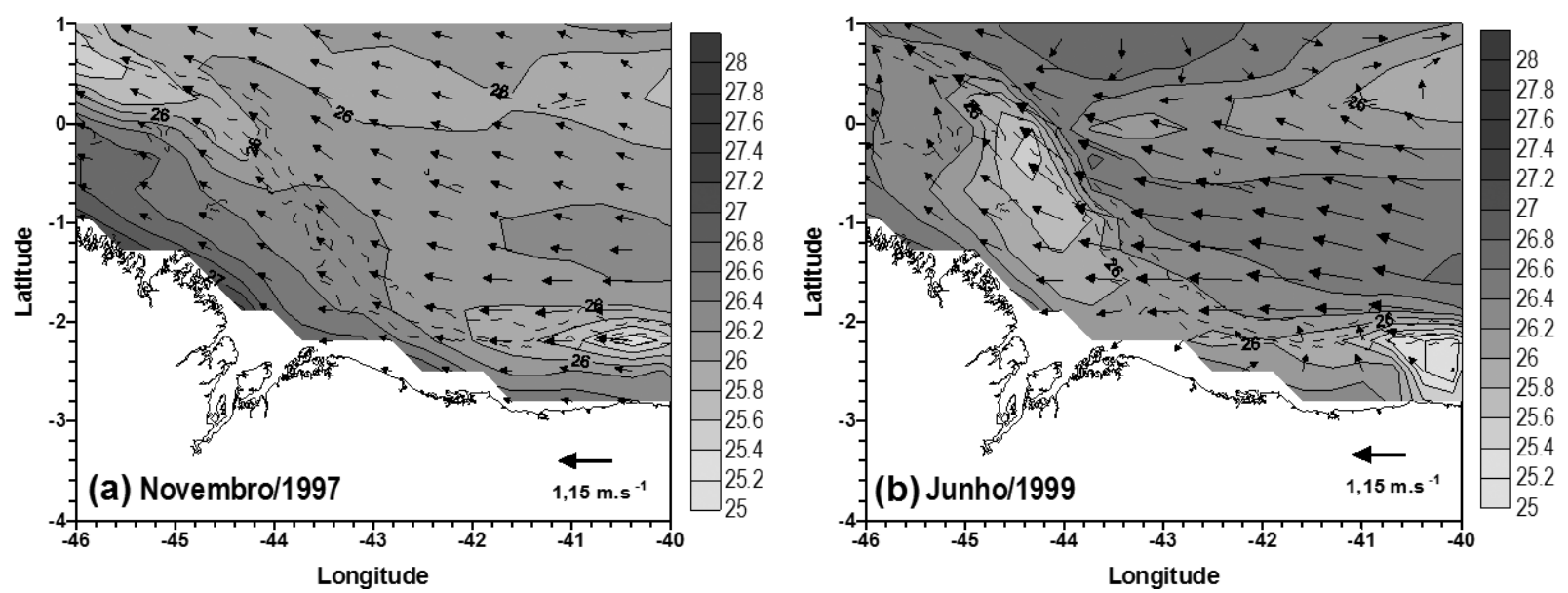

Figura 10 - Distribuição espacial dos valores médios mensais de Temperatura da Superfície do Mar (TSM) e vetores de correntes superficiais, gerados a partir dos resultados numéricos do Experimento ATL6: (a) Novembro/1997; e (b) Junho/1999.

ação do transporte superficial de massa e energia para Noroeste ao longo da quebra da PCM no mês de Junho/1999, quando comparado ao mês de Novembro/1997 (Figs. 10a e 10b).

Outro resultado importante mostrado no experimento numérico é a influência de uma contra corrente no qual transporta água para sudeste ao longo da latitude de $0.7^{\circ} \mathrm{N}$. (Fig. 10b), isto pode justificar a influência de águas provenientes do rio Amazonas sendo transportado para a região de estudo encontrada por Bourlès et al. (1999) e nas coletas de mar de Junho/1999 (Fig. 6b).

Os resultados demonstrados a partir do Transecto 1 indicam que, durante ambos os períodos de coleta, foi registrada uma massa de água subsuperficial com alta concentração de sal $(\geq 36,6)$, dando origem à formação de um núcleo de máxima salinidade que se situou entre 60-100 m de profundidade (Fig. 8). Esta massa d'água salina está relacionada ao núcleo de máxima velocidade da CNB, observado por Bourlès et al. (1999), entre outros, que traz para a região águas de máxima salinidade formadas no giro subtropical do Atlântico Sul (Stramma \& Schott, 1999; Stramma et al., 2003; 2005). Dessa forma, a CNB pode interferir na variação da $E C B$, induzindo uma modificação nas profundidades das linhas isotérmicas e isohalinas que se encontram em subsuperfície (Figs. 7 e 8). As observações hidrográficas confirmam que as ZMix e ZI sot na região oceânica adjacente à PCM é fortemente condicionada à posição e à intensificação destes núcleos de salinidade máxima transportado pelo sistema de CNB/SCNB, o qual podem ser subductados sobre as águas fluviais superficiais de baixa salinidade induzindo a formação de EC B (Fig. 8b).

\section{CONCLUSÕES}

Os resultados das análises dos dados hidrológicos, obtidos na região da Plataforma Continental do Maranhão (PCM) e área oceânica adjacente, permitiram identificar situações distintas com relação às distribuiçõos espaços-temporais de Temperatura $e$ Salinidade da Superfície do Mar (TSM e SSM, respectivamente).

No que se refere à escala espacial, foi possível evidenciar dois padrões de distribuição, em função das forçantes modificadores do balanço térmico e salino. Um primeiro padrão é encontrado na região da Plataforma Continental Interna (limitada pela isóbata $50 \mathrm{~m}$ ), onde as distribuições de salinidade e temperatura são preponderantemente afetadas pelo aporte continental de água doce e de material em suspensão. Esta influência ficou mais evidente nos dados coletados em Junho/1999, época de elevada pluviosidade regional. 0 segundo padrão de distribuição das propriedades termohalinas superficiais na área de estudo corresponde à região oceânica adjacente à Plataforma Continental. Neste caso, verifica-se que os valores superficiais da TSM, nos períodos estudados, podem ser explicados pela influência da corrente de fronteira oeste do Atlântico, dos ventos alísios e pelo aporte de águas de baixa salinidade, principalmente na região de influência da CNB, agindo próximo da quebra da Plataforma Continental.

As observações hidrográficas, os registros de modelo numérico e medidas do satélite TRMM-TMI mostraram menores valores da TSM próximo da quebra da Plataforma, nos meses de Junho/1999 e Novembro/1997.

A comparação entre as distribuições verticais das propriedades termohalinas ao longo de um transecto perpendicular à costa indicou uma pequena elevação das ZMix e ZIsot $(20 \mathrm{~m}$ e 
$40 \mathrm{~m}$ de profundidade) formado uma $E C B$ de $20 \mathrm{~m}$ durante 0 mês de Junho/1999. Esta configuração são resultantes da presença de águas de baixa salinidade em superfície provenientes do aporte de águas fluviais sendo subductadas por núcleos de salinidade máxima em subsuperfície no qual são transportados para a região de estudo pelo sistema de SCNB-CNB, ao longo da fronteira oeste do Atlântico.

Estes fenômenos de larga escala terminam por influenciar decisivamente 0 transporte de energia e de massa ao longo da costa brasileira, bem como as trocas entre águas continentais e oceânicas. Os resultados apresentados neste trabalho constituem uma contribuição para o conhecimento e a conseqüente quantificação destes processos.

\section{AGRADECIMENTOS}

Os autores agradecem à equipe do Subcomitê Regional Norte do Programa REVIZEE, bem como os Comandantes e tripulações do NOC. Antares, Marinha do Brasil, pelo esforço e dedicação demonstrados durante todas as expedições oceanográficas. 0 primeiro autor agradece ainda à Dra. Anne Marie Treguier (LPO/IFREMER) e ao Dr. Bernad Bourlès (LEGOS/RD-Brest) pela disponibilização dos resultados numéricos do Experimento ATL6 do Projeto CLIPPER.

\section{REFERÊNCIAS}

BARNIER B, REYNAUD T, BECKMANN A, BONING C, MOLINES J-M, BARNARD S \& JIA Y. 2001. On the seasonal variability and eddies in the North Brazil Current: insight from model intercomparison experiments. J. Progress in Oceanogr., 44: 195-230.

BLANCK HF. 1999. Using TOPEX Satellite El-Niño altimetry data to introduce thermal expansion and heat capacity concepts in chemistry courses. J. Chem. Educ., 76: 1635-1646.

BOURLÈS B, MOLINARI RL, JOHNS E, WILSON WD \& LEAMAN KD. 1999. Upper layer currents in the western tropical north Atlantic (19891991). J. Geophys. Res., 104: 1361-1375.

BRAINERD KE \& GREGG MC. 1995. Surface mixed and mixing layer depths. Deep-Sea Res. I, 42: 1521-1543.

CIOTTI AM, ODEBRECHT C, FILLMANN G \& MÖLLER Jr. 00. 1995. Freshwater outflow and subtropical convergence influence on phytoplankton biomass on the southern Brazilian continental shelf. Cont. Shelf. Res., 15(14): 1737-1756.

CLIPPER Project team. 2000. 1/6 Atlantic Circulation model forced by the ECMWF climatology: preliminary results. LEGI report number CLIPPER-R2-2000. Disponível em: <http://www. fremer.fr//po/clipper>. Acesso em: 25 jun. 2007.
CIRM. Comissão Interministerial para os Recursos do Mar. 1994. IV Plano Setorial para os recursos do mar (1994-1998). Brasília-DF: 19 pp. CRONIN MF \& McPHADEN MJ. 2002. Barrier layer formation during westerly wind bursts. J. Geophys. Res., 107(C12): 2101-2112.

DeMARIA M, KNAFF JA \& CONNELL BH. 2001. A tropical cyclone genesis parameter for the tropical Atlantic. Weather Forecast, 16: 219-233.

FERRARO RR. 1997. SSM/l derived global rainfall estimates for climatological applications. J. Geophys. Res., 102(C16): 715-735.

FERRARO RR, GRODY NC, WENG F \& BASIST A. 1996. An Eight-Year (1987-1994) Time Series of Rainfall, Clouds, Water Vapor, Snow Cover, and Sea Ice Derived from SSM/I Measurements. Bull. Amer. Meteorol. Soc., 77: 891-905.

FFIELD A. 2005. North Brazil Current rings viewed by TRMM Microwave Imager SST and the influence of the Amazon Plume. Deep-Sea Res. I, 52: $137-160$.

FFIELD A. 2007. Amazon and Orinoco River plumes and NBC Rings: Bystand-ers or participants in hurricane events? J. Climate, 20: 316333.

GENTEMANN C, WENTZ F, MEARS C \& SMITH D. 2004. In situ validation of Tropical Rainfall Measuring Mission microwave sea surface temperatures. J. Geophys. Res., 109(C4): doi: 10.1029/2003JC002092. ISSN: 0148-0227.

GEYER WR, BEARDSLEY RC, LENTZ SJ, CANDELA J, LIMEBURNER R, JOHNS WE, CASTRO BM \& SOARES ID. 1996. Physical oceanography of the Amazon shelf. Cont. Shelf Res., 16: 575-616.

GIBBS RJ. 1970. Circulation in the Amazon river estuary and adjacent Atlantic ocean. J. Mar. Res., 28: 113-123.

GORDON AL. 1986. Interocean exchange of thermocline water. J. Geophysical Res., 91: 5037-5046.

GRUBER A \& KRUEGER AF. 1984. The status of the NOAA outgoing Iongwave radiation data set. Bulletin of the American Meteorological Society, 65: 958-962.

HASTENRATH S. 1984. Interannual variability and annual cycle: mechanisms of circulation and climate in the tropical Atlantic. Mon. Weather. Rev., 112: 1097-1107.

HELLWEGER FL \& GORDON AL. 2002. Tracing Amazon River. water into the Caribbean Sea. J. Mar. Res. 60: 537-549.

JOHNS WE, BEARDSLEY RC, CANDELA J, LIMEBURNER R \& CASTRO BM. 1998. Annual cycle and variability of the North Brazil Current. J. Phys. Oceanogr., 28: 103-128.

LUKAS R \& LINDSTROM E. 1991. The mixed layer of the western equatorial Pacific Ocean. J. Geophys. Res., 96 Supplement, 3343-3357.

MADEC G, DELECLUSE P, IMBARD M \& LÉVY C. 1998. OPA 8.1 Ocean General Circulation Model Reference Manual. Notes du Pôle de Modélisation IPSL, note 11, Dec.1998. 91 pp. 
MARRA J, BIDIGARE RR \& DICKEY TD. 1990. Nutrients and mixing, chlorophyll and phytoplankton growth. Deep-Sea Res. I, 37: 127-143.

MICHEL S \& TREGUIER AM. 2002. Sensitivity of the Equatorial Undercurrent to mixing parameterizations in the CLIPPER model. Rapport DRO/LPO n. 02-16, 0ct. 2002. 75 pp.

MILLER JR. 1976. The salinity effect on a mixed layer ocean model. J. Phys. Res., 6: 29-35.

MOURA AD \& SHUKLA J. 1981. On the dynamics of droughts in northeast Brazil: Observations, theory and numerical experiments with a general circulation model. J. Atmos. Sci., 38: 2653-2675.

NOBRE P \& SHUKLA J. 1996. Variations of sea surface temperature, wind stress, and rainfall over the tropical Atlantic and South America. J. Climate, 9: 2464-2479.

OHLMANN JC, SIEGEL DA \& GAUTIER C. 1996. Ocean mixed layer depth heating and solar penetration: A global analysis. J. Climate, 9: 2265-2280.

REYNAUD T, LEGRAND P, MERCIER H \& BARNIER B. 1998. A new analysis of hydrographic data in the Atlantic and its application to an inverse modelling study. International WOCE newsletter, 32: 29-31.

REYNOLDS RW \& SMITH TM. 1994. Improved global sea surface temperature analyses using optimum interpolation. J. Climate, 7: 929-948.

SCHOTT FA, FISCHER J \& STRAMMA L. 1998. Transports and pathways of the upper-layer circulation in the western tropical Atlantic. J. Phys. Oceanogr., 28: 1904-1928.

SHAPIRO LJ \& GOLDENBERG SB. 1998. Atlantic sea surface temperature and tropical cyclone formation. J. Climate, 11: 578-590.

SILVA AC. 2006. An analysis of water properties in the western tropical Atlantic using observed data and numerical model results. Tese de doutorado, Departamento de Oceanografia, UFPE, Recife/PE, $156 \mathrm{p}$.

SILVA AC, ARAUJO M, MEDEIROS C, SILVA M \& BOURLÈS B. 2005a. Seasonal changes in the mixed and barrier layers in the western equatorial Atlantic. Brazilian Journal of Oceanography, 53(3/4): 83-98.
SILVA AC, ARAUJO M \& BOURLÈS B. 2005b. Variação Sazonal da Estrutura de Massas de Água na Plataforma Continental do Amazonas e área oceânica adjacente. Revista Brasileira de Geofísica, 23(2): 145-157.

SPALL MA. 1991. A diagnostic study of wind and buoyancy driven north Atlantic circulation. J. Geophysical Res., 96: 18509-18518.

SPRINTALL J \& TOMCZAK M. 1990. Salinity considerations in the oceanic surface mixed layer. Ocean Sciences Institute Rep., 36: 1-170.

SPRINTALL J \& TOMCZAK M. 1992. Evidence of the barrier layer in the surface layer of the tropics. J. Geophys. Res., 97: 7305-7316.

STRAMMA L \& SCHOTT F. 1999. The mean flow field of the tropical Atlantic Ocean. Deep-Sea Res. II, 46: 279-303.

STRAMMA L, FISCHER J, BRANDT P \& SCHOTT F. 2003. Circulation, variability and near-equatorial meridional flow in the central tropical Atlantic. In: GONI GJ \& MALANOTTE-RIZZOLI P. (Ed.). Interhemispheric water exchange in the Atlantic Ocean, Elsevier, Amsterdam, pp. 1-22.

STRAMMA L, RHEIN M, BRANDT P, DENGLER M, BÖNING C \& WALTER M. 2005. Upper ocean circulation in the western tropical Atlantic in boreal fall 2000. Deep-Sea Res. I, 52: 221-240.

UNESC0. 1981. Background papers and supporting data on the Practical Salinity Scale 1978, Technical Papers Marine Sc., vol. 37, 144 p.

UNESCO. 1996. Global River Discharge Data Base. Vol. I: Africa, Vol. II: Asia, and Vol. III: Europe.

WENTZ FJ. 1998. Algorithm Theoretical Basis Document: AMSR Ocean Algorithm, Tech. Rept. 110398, Remote Sensing Systems, Santa Rosa, CA.

WENTZ FJ \& MEISSNER T. 2000. Algorithm Theoretical Basis Document (ATBD), Version 2, AMSR Ocean Algorithm, RSS Tech. Proposal 121599A-1, Remote Sensing Systems, Santa Rosa, CA, 59 p.

WENTZ FJ, ASHCROFT PD \& GENTEMANN CL. 2001. Post-launch calibration of the TMI microwave radiometer, IEEE Trans. Geosci. and Remote Sensing, 39(2): 415-422.

\section{NOTAS SOBRE OS AUTORES}

Alex Costa da Silva. Geólogo pela Universidade Federal do Pará (UFPA) em 2000, atuando especificamente no Grupo de Estudos Marinhos e Costeiros da UFPA. Participou do REVIZEE/SCORE-N (Programa de Avaliação do Potencial Sustentável de Recursos Vivos na Zona Econômica Exclusiva/Subcomitê Região Norte), atuando como coordenador da Subárea de Oceanografia Física. Doutorado Sandwich em Oceanografia Física pelo Departamento de Oceanografia da Universidade Federal de Pernambuco (DOCEAN/UFPE) e pelo Institut de Recherche pour le Développement (IRD/Brest/França). Atualmente é Professor Visitante do Centro de Ciências e Tecnologia da Universidade Estadual do Ceará (CCT/UECE), onde atual no Grupo de Pesquisa em Sistemas Costeiros e Oceânicos e no Mestrado em Ciências Físicas Aplicadas da UECE.

Moacyr Araujo. Engenheiro civil pela Universidade Federal de Pernambuco (UFPE), Mestre em Hidráulica e Saneamento pela Universidade de São Paulo (USP) e Doutor em Física e Química do Meio ambiente pelo Institut National Polytechnique de Toulouse (INPT/França). Professor Adjunto do Departamento de Oceanografia da UFPE desde 1998, Iotado no Laboratório de Oceanografia Física Estuarina e Costeira (LOFEC), onde vem desenvolvendo atividades de ensino e pesquisas em 
Oceanografia Física costeira e oceânica. Vice-coordenador da Subárea de Oceanografia Física do Programa REVIZEE/SCORE-NE (Programa de Avaliação do Potencial Sustentável de Recursos Vivos na Zona Econômica Exclusiva/Subcomitê Região Nordeste). Pesquisador 2/Bolsista do CNPq.

Lidriana de Souza Pinheiro. É geógrafa pela Universidade Estadual do Ceará (UECE), no qual participou como pesquisadora no Grupo de Pesquisa Sistemas Costeiros e Oceânicos da UECE. Obteve os títulos de Mestre em Geografia pela UECE na área de hidrodinâmica costeira e estuarina e de Doutorado em Oceanografia, na UFPE. Atualmente é Professora Adjunta do Departamento de Geociências do Centro de Ciências e Tecnologia. Pesquisadora 2/Bolsista do CNPq. 